\title{
Immune activation and regulatory $T$ cells in Mycobacterium tuberculosis infected lymph nodes
}

\author{
Karima Sahmoudi ${ }^{1}$, , Hassan Abbassi ${ }^{3}$, Nada Bouklata ${ }^{4}$, Mohamed Nouredine El Alami ${ }^{3}$, Abderrahmane Sadak ${ }^{2}$, \\ Christopher Burant ${ }^{5}$, W. Henry Boom ${ }^{6}$, Rajae El Aouad ${ }^{1}$, David H. Canaday ${ }^{6+}$ and Fouad Seghrouchni ${ }^{1{ }^{*}}$ (D)
}

\begin{abstract}
Background: Lymph node tuberculosis (LNTB) is the most frequent extrapulmonary form of tuberculosis (TB). Studies of human tuberculosis at sites of disease are limited. LNTB provides a unique opportunity to compare local in situ and peripheral blood immune response in active Mycobacterium tuberculosis (Mtb) disease. The present study analysed T regulatory cells (Treg) frequency and activation along with CD4+ T cell function in lymph nodes from LNTB patients.

Results: Lymph node mononuclear cells (LNMC) were compared to autologous peripheral blood mononuclear cells (PBMC). LNMC were enriched for CD4+ T cells with a late differentiated effector memory phenotype. No differences were noted in the frequency and mutifunctional profile of memory CD4+ T cells specific for Mtb. The proportion of activated CD4+ and Tregs in LNMC was increased compared to PBMC. The correlation between Tregs and activated CD4+ T cells was stronger in LNMC than PBMC. Tregs in LNMC showed a strong positive correlation with Th1 cytokine production (IL2, IFNy and TNFa) as well as MIP-1a after Mtb antigen stimulation. A subset of Tregs in LNMC co-expressed HLA-DR and CD38, markers of activation.

Conclusion: Further research will determine the functional relationship between Treg and activated CD4+ T cells at lymph node sites of Mtb infection.
\end{abstract}

Keywords: Tuberculosis, Lymphadenitis, Lymph node, Treg cells, conventional T cell, activation

\section{Background}

Mycobacterium tuberculosis (Mtb) infection is a major global health problem with approximately 10.4 million cases and 1.4 million deaths from tuberculosis (TB) in 2015 [1]. Furthermore, one-third of the world's population is thought to be infected by Mtb. Extra pulmonary TB represents approximately $20 \%$ of clinical TB disease. Lymph node tuberculosis (LNTB) is the most frequent extrapulmonary form [1].

Cellular immune responses play a pivotal role in control of Mtb infection with CD4+ T cells having the central role. After infection CD4+ T cells undergo activation manifested by expression of surface molecules including

\footnotetext{
* Correspondence: fseghrouchni@yahoo.fr

${ }^{\dagger}$ David H. Canaday and Fouad Seghrouchni contributed equally to this work. ${ }^{1}$ Laboratory of Cellular Immunology, National Institute of Hygiene, 27,

Avenue Ibn Batouta, PB 769, 11400 Rabat, Morocco

Full list of author information is available at the end of the article
}

HLA-DR and CD38 [2, 3]. Functionally, CD4+ T cells control infection by producing Th1 and Th17 cytokines [4]. Polyfunctional $\mathrm{T}$ cells, defined by their ability to co-express more than one cytokine, have been associated with protection against Mtb disease [4-6].

At sites of infection, immune responses are modulated by $\mathrm{T}$ regulatory cells (Tregs) $[7,8]$. Tregs express CD3, $\mathrm{CD} 4$, high levels of $\mathrm{CD} 25$, low levels of the IL-7 receptor $\alpha$-chain (CD127) and the intracellular marker forkhead box p3 (FoxP3) [9].

The relationship between Tregs and immune activation at sites of Mtb disease is not clear [10, 11]. The objective of the present study was to evaluate the interaction between Tregs and the function and activation of CD4+ T cells in lymph node vs. the peripheral blood compartments in persons with LNTB.

(c) The Author(s). 2018 Open Access This article is distributed under the terms of the Creative Commons Attribution 4.0 International License (http://creativecommons.org/licenses/by/4.0/), which permits unrestricted use, distribution, and reproduction in any medium, provided you give appropriate credit to the original author(s) and the source, provide a link to the Creative Commons license, and indicate if changes were made. The Creative Commons Public Domain Dedication waiver (http://creativecommons.org/publicdomain/zero/1.0/) applies to the data made available in this article, unless otherwise stated. 


\section{Methods}

\section{Subjects and preparation of immune cells}

Eighteen patients (5 men, 13 women, age range 17-60 years) were recruited in the Hassan II University Hospital of Fes (Morocco) among patients with cervical lymphadenitis. Active LNTB was diagnosed by history, physical examination, and lab studies by experienced clinicians. The diagnosis of LNTB was based on a combination of clinical symptoms, pathology and response to TB drug therapy. Clinical symptoms associated with lymphadenitis included local lymphadenopathy, weight loss, fever, sweats, and anorexia. Histopathological evidence consisted of the presence of a granulomatous lesion with caseation in excisional biopsy specimens. Pulmonary radiography and HIV serology were performed to exclude pulmonary TB and HIV infection respectively. All LNTB cases were newly diagnosed and none had received anti-TB chemotherapy before sample collection. Tuberculin skin test results were positive (induration $\geq 10 \mathrm{~mm}$ ) for 15 out of 18 patients (83\%). All patients were BCG vaccinated, and none reported contact with a case of pulmonary TB.

For all patients, the affected lymph node was in the neck and was surgically removed. In addition, $10 \mathrm{ml}$ of peripheral blood was collected before starting anti-TB treatment. One portion of the lymph node was used for histological examination, and the other for isolation of lymph node mononuclear cells (LNMC) for immunologic studies.

Biopsy specimens were crushed gently in tissue culture medium. LNMC were spun and separated using Ficoll-Hypaque density centrifugation. Peripheral blood mononuclear cells (PBMC) were isolated from heparinized venous blood under endotoxin-free conditions by Ficoll-Hypaque (SIGMA) density centrifugation. Cells were cryopreserved and stored in liquid nitrogen until shipment by a cryoshipper to Case Western Reserve University for immunological studies.

\section{Phenotypic and functional study of T cells}

PBMC and LNMC $\left(10^{6} /\right.$ tube) were stimulated with a pool of 34 overlapping peptides from Mtb-antigen ESAT6/CFP10 at $6.25 \mathrm{ug} / \mathrm{ml}$ per peptide (New England peptide, Gardner, MA), M. tuberculosis CDC1551 whole cells lysate (Mtb lysate) (BEI Resources) or staphylococcal enterotoxin B (SEB, $2 \mu \mathrm{g} / \mathrm{ml}$, Sigma) overnight at 37 ${ }^{\circ} \mathrm{C}$ in $5 \% \mathrm{CO}_{2}$. Unstimulated PBMC and LNMC served as negative controls. Anti-CD28/CD49d ( $1 \mu \mathrm{g} / \mathrm{ml}$ each, eBioscience and Biolegend) was added to each tube during stimulation and brefeldin A ( $5 \mu \mathrm{g} / \mathrm{ml}$, Sigma) was added $2 \mathrm{hr}$ later. After stimulation, cells were washed with PBS and surface stained with anti-CCR7-PE-Cy7 (BD Bioscience) for $15 \mathrm{~min}$ at $37{ }^{\circ} \mathrm{C}$, then live dead yellow (Invitrogen), anti-CD14-BV570, anti-CD4-APC/Cy7,
anti-CD8-BV510 (all Biolegend) and anti-CD45RA-PE/ TR (Invitrogen) were added and incubated at RT for 25 min. Afterward cells were washed, permeabilized (Cytofix/Cytoperm Kit, BD Pharmingen) according to the manufacturer's instructions and stained for intracellular expression with anti-CD3-PerCP, anti-IFN $\gamma$-Alexa700, anti-IL2-APC, anti-TNF $\alpha$ - Pacific Blue, anti-IL17-BV711 (all Biolegend) and anti-MIP-1 $\alpha$-FITC (R\&D). Cells were then washed, fixed in $1 \%$ paraformaldehyde and $1 \times 10^{6}$ total events collected from each sample on an LSR-II flow cytometer (BD). Net responding cells for each cytokine were calculated by subtracting the no antigen condition (medium only) from the antigen simulated result. The analysis of all functional markers expressed after stimulation were done on viable total memory CD4+ and CD8+ T cells. Memory phenotype was determined by CCR7 and CD45RA expression. Naïve T cells were CD45RA+/CCR7+, central memory (CM) cells were CD45RA-/CCR7+, effector memory (EM) cells were CD45RA-/CCR7-and effector cells (E) were CD45RA +/CCR7-.

To identify Tregs and activated $\mathrm{T}$ cells, PBMC and LNMC were surface stained with live dead yellow (Invitrogen), anti-CD3-APC/Cy7, anti-CD4-PerCP, anti-CD8 -Alexa700, anti-CD25-APC, anti-HLA-DR-FITC, antiCD38-PE/Cy7(all Biolegend), and anti-CD127-BV6 50(BD Bioscience), and incubated at RT for $25 \mathrm{~min}$. After, cells were washed, permeabilized and intracellular stained with, anti-FoxP3-PE (eBioscience) or isotype-m atched negative control for gating purposes.

Plots were analyzed using FlowJo software (version 6.1.1; Tree Star, Ashland, OR, USA). Boolean analysis on Flow Jo and SPICE (NIAID, NIH, USA) was used to assess cytokine polyfunctionality.

\section{Statistical analysis}

Statistical analysis was performed using the paired Student's t test for comparisons of PBMC and LNMC. P value for comparison of polyfunctional profile was done using SPICE software. Significance of correlations was analyzed by the nonparametric Spearman test. A $p$ value of $\leq 0.05$ was considered significant. Data were analyzed by Statistical Package for the Social Sciences (SPSS) software (IBM) and the GraphPad Prism software, version 5.00 for Windows (GraphPad Software, San Diego).

\section{Results}

\section{Phenotypic and cytokine profile of CD4+ T cells in LNMC and PBMC}

We first compared memory phenotypes of $\mathrm{T}$ lymphocyte subsets in LNMC and PBMC. LNMC were significantly enriched for CD4 $+\mathrm{T}$ cells $[80.7 \pm 5.6 \%$ vs. $68.0 \pm 6.6 \%(p=0.0015)]$ (Fig. 1a). CD8+ T cells were concomitantly lower in LNMC compared to PBMC 

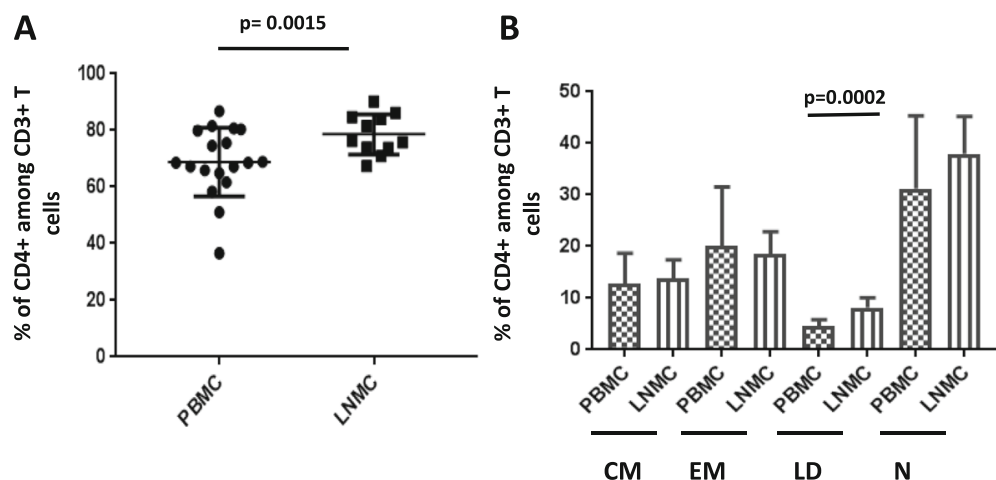

CM: central memory, EM: effecter memory, LD: late differentiated memory cells, $\mathrm{N}$ : naive.

Fig. 1 Phenotypic and functional T-cell subset distribution in PBMC and LNMC. Relative frequencies of CD4+T cells (a) and memory subsets of CD4+ T cells (b) among all CD3+ T cells. Means from 18 subjects are shown and error bars represent standard deviations

[17.6 $\pm 5.8 \%$ vs. $27.4 \pm 11.7 \%(p=0.0055)]$ (Additional file 1). Memory subsets of CD4+ T cells were defined according to expression of CD45RA and CCR7 and only the effector subset was modestly increased in LNMC compared to PBMC ( $p=0.0002)$ (Fig. 1b).

$\mathrm{T}$ cell functional profiles in response to Mtb antigens were compared between LNMC and PBMC. IFN $\gamma$, IL2,
TNF $\alpha$, IL17, and MIP- $1 \alpha$ production by CD $4+T$ cells in PBMC and LNMC in response to Mtb RVL were not different (Fig. 2a). Similarly CD4+ T cell responses in response to ESAT6/CFP10 peptides were not different between LNMC and PBMC (Additional file 2).

No significant differences were observed in the polyfunctionality of total memory CD4+ T cells in LNMC

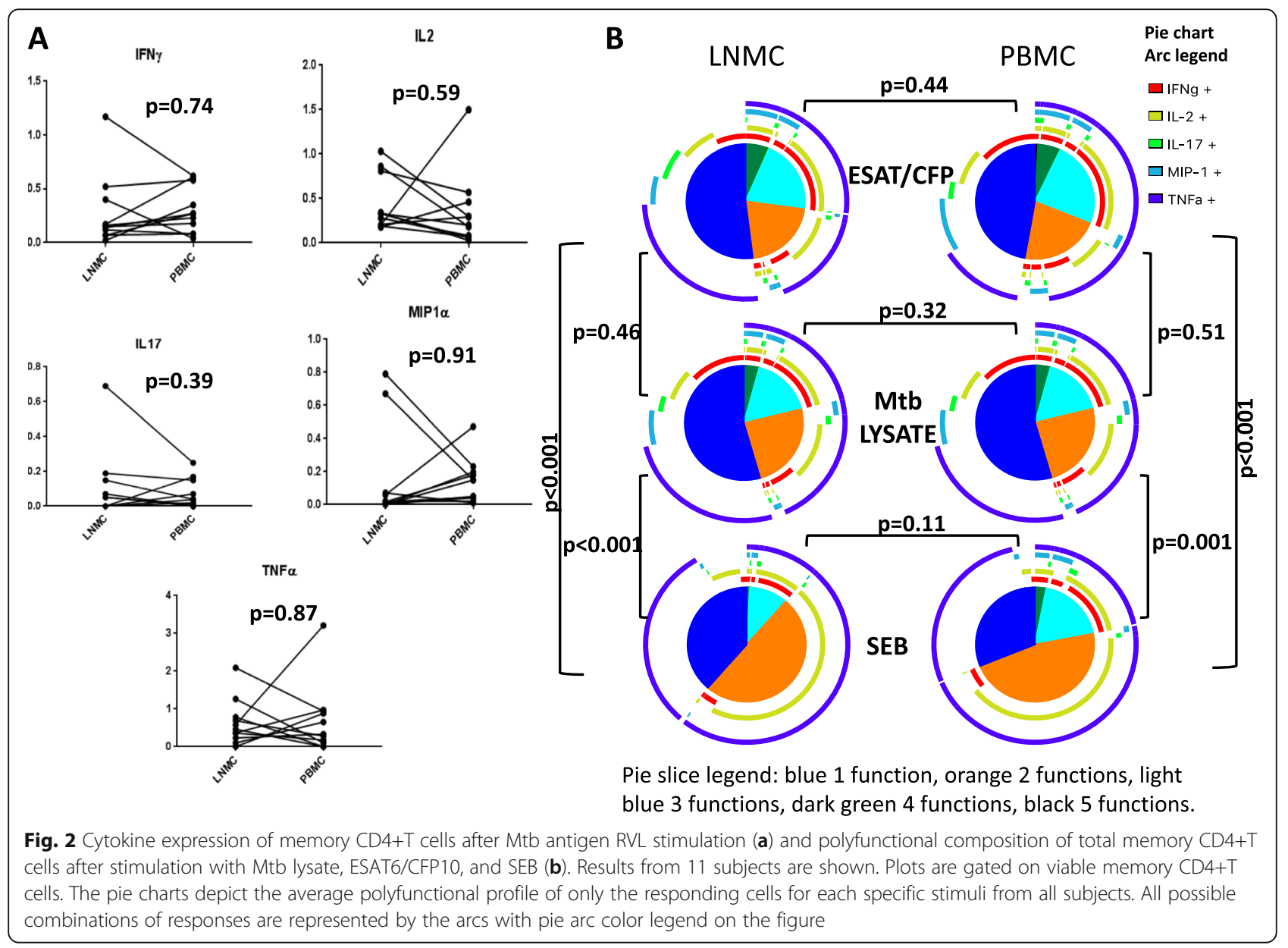


when compared to PBMC for the same stimuli (Fig. 2b all three rows with side to side comparison). Polyfunctionality of total memory $\mathrm{CD} 4+\mathrm{T}$ cells in response to ESAT6/CFP10 peptides and Mtb lysate were significantly different from that in response to SEB in both PBMC and LNMC indicating a difference in Mtb-specific cells as a group (Fig. 2b, top 4 pies vs. bottom 2 comparison), but no differences were found in the polyfunctionality in response to Mtb-specific antigens, ESAT6/CFP10 peptides and Mtb lysate (Fig. 2b top two and middle two comparison).

\section{Distribution of activated T cells and Tregs in LNMC and PBMC}

We measured the frequency of activated conventional CD4+ T cells and Tregs in LNMC and PBMC. Activation was based on the expression of HLA-DR and CD38. Tregs were identified as CD4+, CD25+, FoxP3+ and CD127dim. An increased proportion of activated CD4+ HLA-DR+CD38+ T cells $(p<0.0001)$ and Treg CD4+ CD25+FoxP3+CD127dim $(p=0.0089)$ in LNMC compared to PBMC was observed (Fig. 3). A positive correlation between the frequency of total activated $\mathrm{CD} 4+\mathrm{T}$ cells and Tregs was observed within LNMC $(r=0.676$, $p=0.008)$ and PBMC ( $r=0.549, p=0.018)$ (Fig. 4).

We compared, among Tregs in LNMC, the proportion of cells expressing activation markers. More than $90 \%$ of CD25+ FoxP3+CD127dim cells expressed HLA-DR and/ or CD38. Furthermore, the predominant Treg subpopulation in both LNMC and PBMC was the one expressing HLA-DR and CD38 simultaneously (Fig. 5).

\section{Treg correlation with Mtb-antigen induced cytokine production}

We determined the correlation between the proportion of Tregs and cytokine producing CD4+ $\mathrm{T}$ cells after overnight Mtb-antigen activation in LNMC and PBMC. There was a positive correlation between the proportion of Tregs and Th1 cytokine production (IL2 and IFN $\gamma$ ) as well as MIP-1 $\alpha$ following stimulation by Mtb lysate antigen within LNMC but not among PBMC (Table 1). A similar correlation was found after stimulation by $\mathrm{Mtb}$ ESAT6/CFP10 peptides while no correlation was found after SEB mitogen stimulation (data not shown).

\section{Discussion}

The outcome of the immune response to Mtb results from the simultaneous involvement of activating and regulatory mechanisms $[8,11]$. The nature of the relationship between conventional $\mathrm{T}$ cells and Tregs during active TB is still not clear although this interaction has been studied in different forms of TB $[10,11]$. Increased expression of activation markers on T cells $[12,13]$ and higher levels of Tregs $[7,8]$ have been described in peripheral blood of patients with TB. Nevertheless, local immune responses may differ from those in peripheral blood and exploring this interaction in the site of active infection will give important clues about their involvement in protection or pathogenesis $[14,15]$. The present study sought to evaluate the relationships between Tregs and conventional CD4 $+\mathrm{T}$ cells in lymph nodes and peripheral blood during TB lymphadenitis.

We found a higher proportion of CD4+ $\mathrm{T}$ cells in LNMC compared to PBMC. This is in agreement with previous studies reporting an increase in the proportion of CD4+ T cells in the blood of TB patients compared to uninfected controls and a much higher number of CD4+ T cells at the site of infection [16, 17]. Except for modest elevation in effector cells in LNMC, no difference was found in the relative frequency of memory CD4+ $\mathrm{T}$ cell subsets between PBMC and LNMC. Others have shown that Mtb-specific CD4+ T cells in bronchoalveolar and pleural fluids are mainly of the memory phenotype $[18,19]$. In LNMC we find that up to $40 \%$ of $\mathrm{CD} 4+\mathrm{T}$ cells were naïve.

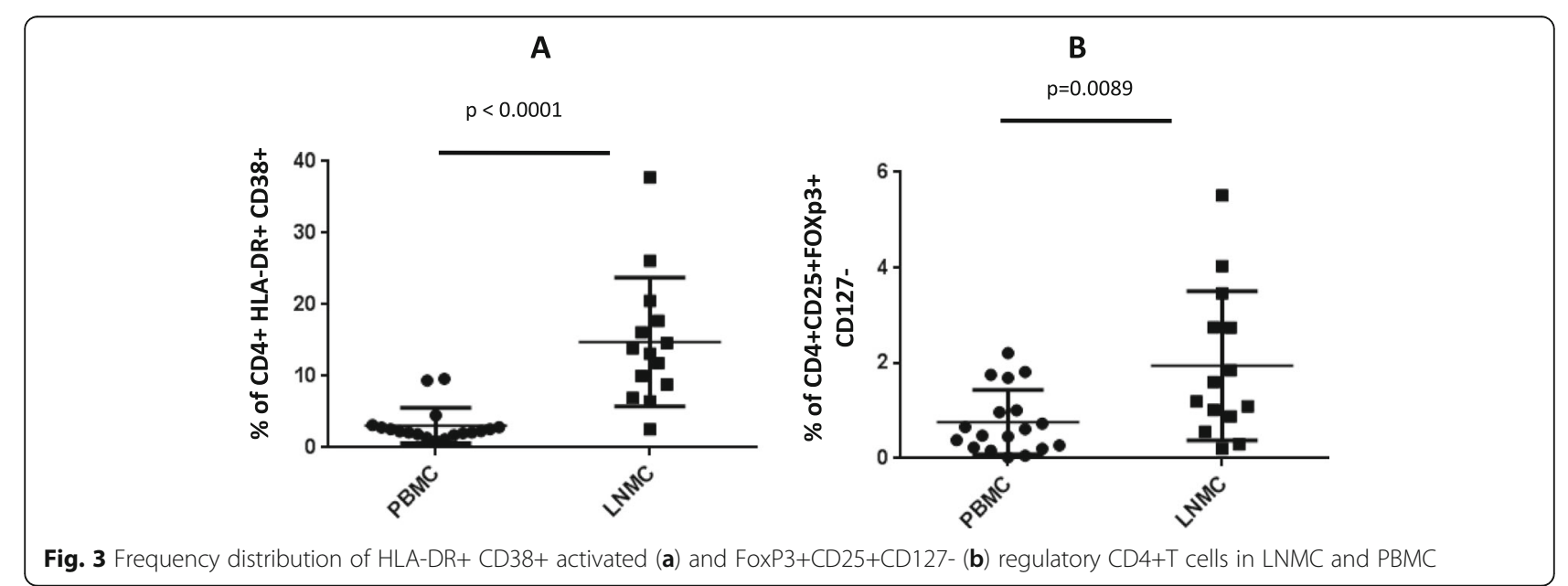


A

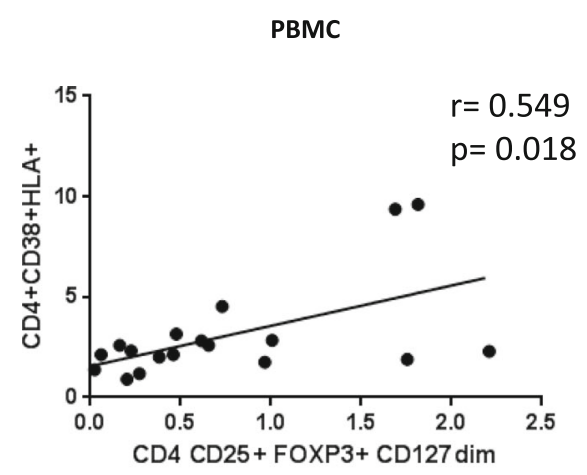

B

LNMC

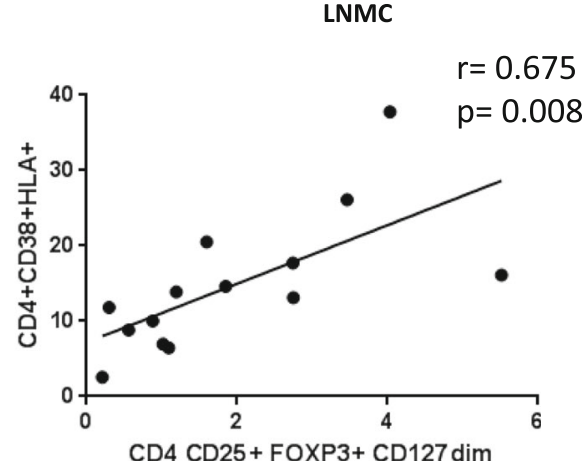

Fig. 4 Ex vivo frequencies of Tregs correlated with the ex-vivo frequencies of CD4+ activated cells in PBMC (a) and LNMC (b)

Th1 and Th17 Mtb-specific T cells contribute to the defense against progressive Mtb infection. Particularly, TB lymphadenitis was characterized by elevated frequencies of Th1 and Th17 cells in peripheral blood [20]. When we measured intracellular production of Th1 cytokines (IFN $\gamma$, IL2 and TNF $\alpha$ ), IL17 and MIP-1 $\alpha$, we were surprised to not find an increase in the frequencies of Mtb-specific cytokine producing cells in LNMC vs. PBMC. LNMC were generated from a large block of excised lymph node tissue that included granulomatous and non-granulomatous areas which may have affected our ability to detect higher frequencies of Mtb-specific cells in LNMC than PBMC.

Polyfunctional $\mathrm{T}$ cells are correlated with protection in some studies $[5,6,21]$ and with disease activity in others $[22,23]$. In our case, no differences were observed in the proportion and polyfunctional qualities of the Mtb-responsive CD4+ $\mathrm{T}$ cells between LNMC and PBMC. Comparing polyfunctionality in CD4+ $\mathrm{T}$ cells responding to Mtb-antigen vs. SEB showed a significant difference with SEB eliciting a more TNFa dominated response. This supports that the Mtb-specific responses were different from those of the whole memory CD4+ T cell pool.

To analyze the interaction between conventional activated $\mathrm{CD} 4+\mathrm{T}$ cells and Tregs in the lymph node during active $\mathrm{TB}$, we measured the frequency of $\mathrm{CD} 4+\mathrm{T}$ cells expressing CD38 and HLA-DR. These immune activation markers were described as substantially elevated in subjects with active TB [24]. CD4+ T cells were more activated in lymph node compared to blood. The increased proportion of activated T cells in LNMC likely reflects more exposure to Mtb antigens. The selective accumulation is likely the result of both active recruitment and local expansion of T cells at this site of Mtb replication [25, 26].

Tregs were identified by selecting CD4+ cells with high-level expression of CD25, low-level expression of CD127, and expression of FoxP3. Tregs were also increased in LNMC in response to local immune activation possibly to control immune induced damage $[3,26$, 27]. In accordance with the previous study [10], our data reveal a positive correlation between Treg and CD4+ activated cells within PBMC but this correlation was stronger in LNMC. Tregs co-expressing HLA-DR and CD38

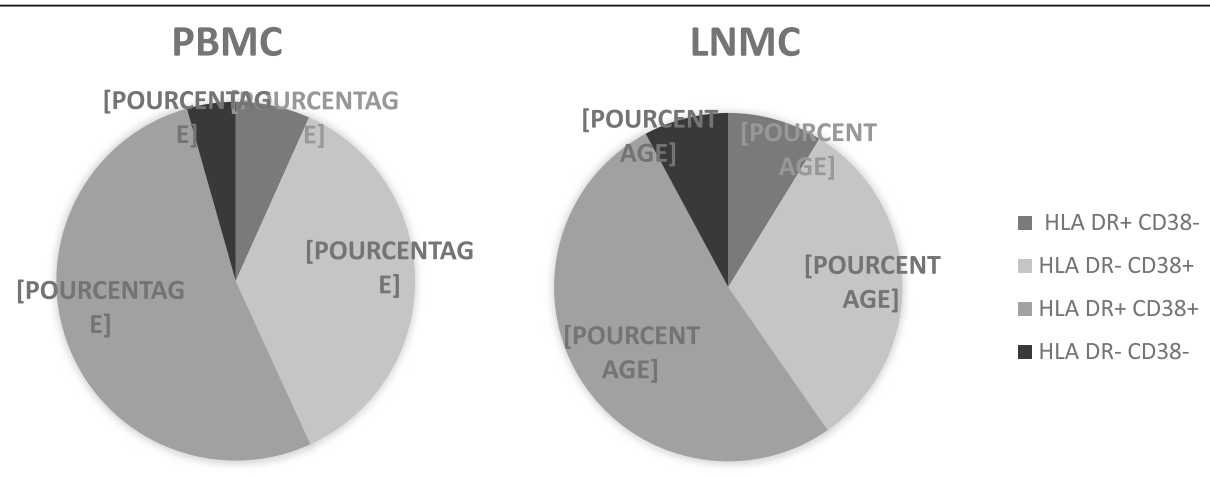

Fig. 5 Distribution of activation markers within CD4+CD25+FoxP3+CD127dim Tregs in PBMC and LNMC 
Table 1 Correlation of the ex vivo frequencies of Tregs with the frequencies of CD4+T cells expressing IFNy, IL2, TNFa, IL17 and MIP1a following Mtb lysate antigen stimulation in PBMC and LNMC

\begin{tabular}{|c|c|c|c|c|}
\hline & \multicolumn{4}{|l|}{ Treg } \\
\hline & \multicolumn{2}{|l|}{ PBMC } & \multicolumn{2}{|c|}{ LNMC } \\
\hline & $r$ & $p$ & $r$ & $p$ \\
\hline $\mathrm{IFN}-\gamma$ & -0.19 & 0.60 & 0.66 & 0.04 \\
\hline IL2 & -0.04 & 0.90 & 0.71 & 0.02 \\
\hline TNF-a & -0.02 & 0.96 & 0.48 & 0.16 \\
\hline IL17 & -0.23 & 0.52 & 0.45 & 0.12 \\
\hline MIP-1a & -0.04 & 0.91 & 0.95 & $<0.001$ \\
\hline
\end{tabular}

markers were frequent in the LNMC and PBMC. The ex-vivo MHC II expressing Tregs are believed to be a functionally mature distinct Treg subset implicated in contact-dependent in vitro suppression [28]. A positive correlation between Treg proportion and frequency of memory Mtb-specific CD4+ T cells expressing each individual measured Th1 function was observed in LNMC but not in PBMC. The predominance of activated Tregs in LNMC and the correlation of Tregs with activated CD4+ $\mathrm{T}$ cells and CD4+ T cells expressing Th1 cytokines suggests a regulatory activity specific and enhanced in the lymph node. An alternate hypothesis could be that the Treg are just expanding at tissue sites but not necessarily for regulatory purposes. The absence of an expected higher proportion of Th1 producing CD4+T cells in LNMC compared to PBMC supports the hypothesis that the Treg/CD4 correlation reflected a negative feedback for excess Th1 cytokine production by increasing suppressive Tregs. Recent data suggest that IFN $\gamma$ increases Treg suppressive function for control of Th1 responses [29, 30]. A limitation of the study is that we did not have any blood or lymph node material in healthy BCG-vaccinated or latently infected individuals available to contrast to the TB lymphadenitis subjects. Contrasting these cohorts in future studies as well as further research on the function of Tregs and their modulation of immune responses in TB lymphadenitis are needed. The current study will help develop an optimal approach to such supplementary exploration.

\section{Conclusion}

This study has important original findings regarding local immune responses in active LNTB. We found no Th1, Th17 or MIP-1 $\alpha$ production differences by Mtb-specific CD4+ T cells in total LNMC vs. PBMC. Tregs were positively correlated with Th1 expressing Mtb-specific CD4+ $\mathrm{T}$ cells in LNMC but not in PBMC. Activated HLA-DR +CD38+Tregs were more abundant, suggesting modulation by Tregs of immune responses in LNMC. We suggest that increased Tregs at the lymph node site of active Mtb infection regulates the immune response. Whether this is advantageous to the host or not remains to be determined.

\section{Additional files}

Additional file 1: CD8+ T-cell subset distribution in PBMC and LNMC. Relatives frequencies of CD8+ T cells among all CD3+ T cells. Means from 18 subjects are shown and error bars representing standard deviations. (PPTX $51 \mathrm{~kb}$ )

Additional file 2: Cytokine expression of memory CD4+T cells after ESAT6/CFP10 stimulation. Results from 11 subjects are shown. Plots are gated on viable memory CD4+T cells. (PPTX $91 \mathrm{~kb}$ )

\section{Abbreviations}

LNTB: Lymph node TB; TB: Tuberculosis; Mtb: Mycobacterium tuberculosis; Treg: T regulatory cells; LNMC: Lymph node mononuclear cells;

PBMC: Peripheral blood mononuclear cells; CD127: IL-7 receptor a-chain; FoxP3: The intracellular marker forkhead box p3; Mtb lysate: $M$. tuberculosis CDC1551 whole cells lysate; SEB: Staphylococcal enterotoxin B; N: Naïve T cells; CM: Central memory cells; EM: Effector memory cells; E: Effector cells

\section{Acknowledgements}

The authors would like to thank all patients for their participation. They also would like to thank all the health and laboratory professional that facilitate the realization of this work.

\section{Funding}

This study was supported by the Hassan II Academy for Sciences and techniques of Morocco (IMMGEN project), NIH Al108972, NIH Al080313, NIH P30 Al036219, NIAID Contract No. HHSN266200700022C / NO1-Al-70022, and VA GRECC.

\section{Availability of data and materials}

All the raw data were kept in the experiment book, or as electronic files such as acquired by flow cytometer will be available on request.

\section{Authors' contributions}

This study was designed by KS, WHB, RE, DHC and FS. HA, NB and MN were the key investigators that assisted in design of the clinical aspects of the study then recruited, treated, and collected clinical data on the subjects. Data analysis, interpretation and statistical analysis were performed by KS, AS, $\mathrm{CB}, \mathrm{DHC}$ and FS. KS, DHC and FS wrote the first draft and AS, WHB, RE, FS and $\mathrm{DHC}$ contributed to the final manuscript. All authors read and approved the final manuscript.

\section{Ethics approval and consent to participate}

The study protocol was approved by the two Ethical Committees for Biomedical Research; Faculty of Medicine and Pharmacy, Mohammed V University of Rabat (Morocco) and University Hospitals of Cleveland Institutional Review Board (US). Informed consent was obtained from each patient according to the National Ethics Committee.

Consent for publication

Not applicable

Competing interests

The authors declare that they have no competing interests.

\section{Publisher's Note}

Springer Nature remains neutral with regard to jurisdictional claims in published maps and institutional affiliations.

\section{Author details}

${ }^{1}$ Laboratory of Cellular Immunology, National Institute of Hygiene, 27, Avenue Ibn Batouta, PB 769, 11400 Rabat, Morocco. ${ }^{2}$ Faculty of Sciences, University Mohammed V Agdal, Rabat, Morocco. ${ }^{3}$ Department of ENT, Maxillo- facial, Reconstructive and Plastic Surgery, University Hospital Hassan II, Fes, Morocco. ${ }^{4}$ National Reference Laboratory of Mycobacteriology, the National Institute of Hygiene, Rabat, Morocco. ${ }^{5}$ Case Western Reserve 
University School of Nursing, Cleveland, USA. ${ }^{6}$ TB Research Unit and Division of Infectious Diseases, Case Western Reserve University, University Hospitals of Cleveland and Cleveland VA, Cleveland, OH, USA.

Received: 19 January 2018 Accepted: 11 October 2018

Published online: 08 November 2018

\section{References}

1. WHO, Global tuberculosis control: WHO Report 2016.

2. Rodrigues DS, Medeiros EA, Weckx LY, Bonnez W, Salomao R, Kallas EG. Immunophenotypic characterization of peripheral T lymphocytes in Mycobacterium tuberculosis infection and disease. Clin Exp Immunol. 2002; 128:149-54.

3. Hertoghe T, Wajja A, Ntambi L, Okwera A, Aziz MA, Hirsch C, Johnson J, Toossi Z, Mugerwa R, Mugyenyi P, Colebunders R, Eller J, Vanham G. T cell activation, apoptosis and cytokine dysregulation in the (co) pathogenesis of HIV and pulmonary tuberculosis (TB). Clin Exp Immunol. 2000;122:350-7.

4. Gideon HP, Phuah J, Myers AJ, Bryson BD, Rodgers MA, Coleman MT, Maiello P, Rutledge T, Marino S, Fortune SM, Kirschner DE, Lin PL, Flynn JL. Variability in tuberculosis granuloma T cell responses exists, but a balance of pro- and anti-inflammatory cytokines is associated with sterilization. PLoS Pathog. 2015;11(1):e1004603. https://doi.org/10.1371/..ppat.1004603.

5. Day CL, Abrahams DA, Lerumo L, Janse van Rensburg E, Stone L, O'Rie T, Pienaar B, de Kock M, Kaplan G, Mahomed H, Dheda K, Hanekom WA. Functional capacity of Mycobacterium tuberculosis-specific $T$ cell responses in humans is associated with mycobacterial load. J Immunol. 2011:187: 2222-32. https://doi.org/10.4049/j immunol.1101122.

6. Harari A, Rozot V, Enders FB, Perreau M, Stalder JM, Nicod LP, et al. Dominant TNF-a+ Mycobacterium tuberculosis-specific CD4+ T cell responses discriminate between latent infection and active disease. Nat Med. 2011;17:372-6. https://doi.org/10.1038/nm.2299 93.

7. Guyot-Revol V, Innes JA, Hackforth S, Hinks T, Lalvani A. Regulatory T-cells are expanded in blood and disease sites in patients with tuberculosis. Am J Respir Crit Care Med. 2006; 7:803-10

8. Hougardy JM, Place S, Hildebrand M, Drowart A, Debrie AS, Locht C, Mascart F. Regulatory T-cells depress immune responses to protective antigens in active tuberculosis. Am J Respir Crit Care Med. 2007:4:409-16.

9. Rodríguez-Perea AL, Arcia ED, Rueda CM, Velilla PA. Phenotypical characterization of regulatory T cells in humans and rodents. Clin Exp Imm. 2016;185(3):281-91.

10. Wergeland I, Aßmus J, Dyrhol-Riise AM. T Regulatory Cells and Immune Activation in Mycobacterium tuberculosis Infection and the Effect of Preventive Therapy. Scand J Imm. 2011;73:234-42.

11. De Almeida AS, Fiske CT, Sterling TR, Kalamsa SA. Increased Frequency of Regulatory T Cells and T Lymphocyte Activation in Persons with Previously Treated Extrapulmonary Tuberculosis. Clin Vaccine Immunol. 2012;19:45-52.

12. Baecher-Allan C, Brown JA, Freeman GJ, Hafler DA. CD4+CD25high regulatory cells in human peripheral blood. J Immunol. 2001:167:1245-53.

13. Baecher-Allan C, Wolf E, Hafler DA. Functional analysis of highly defined, FACS-isolated populations of human regulatory CD4+ CD25+ T cells. Clin Immunol. 2005;115:10-8.

14. Nemeth J, Rumetshofer R, Winkler HM, Burghuber OC, Müller C, Winkler S. Active tuberculosis is characterized by an antigen specific and strictly localized expansion of effector T cells at the site of infection. Eur I Immunol. 2012:42(11):2844-50

15. Diedrich CR, O'Hern J, Gutierrez MG, Allie N, Papier P, Meintjes G, Coussens AK, Wainwright H, Wilkinson RJ. Relationship between HIV Coinfection, Interleukin 10 Production, and Mycobacterium tuberculosis in Human Lymph Node Granulomas. J Infect Dis. 2016;214(9):1309-18.

16. Wang T, Lv M, Qian Q, Nie Y, Yu L, Hou Y. Increased frequencies of T helper type 17 cells in tuberculous pleural effusion. Tuberculosis. 2011;91:231-7.

17. Rumetshofer R, Winkler HM, Burghuber OC, Müller C, Winkler S. Active tuberculosis is characterized by an antigen specific and strictly localized expansion of effector T cells at the site of infection. Eur J Immunol. 2012; 42(11):2844-50.

18. El Fenniri L, Toossi Z, Aung H, El Iraki G, Bourkkadi J, Benamor J, Laskri A Berrada N, Benjouad A, Mayanja-Kizza H, Betts MR, El Aouad R, Canaday DH. Polyfunctional mycobacterium tuberculosis-specific effector memory CD4+ T cells at sites of pleural TB. Tuberculosis. 2011;91:224-30.

19. Chiacchio T, Petruccioli E, Vanini V, Butera O, Cuzzi G, Petrone L, Matteucci G, Lauria FN, Franken KL, Girardi E, Ottenhoff TH, Goletti D. Higher
Frequency of T-Cell Response to M. tuberculosis Latency Antigen Rv2628 at the Site of Active Tuberculosis Disease than in Peripheral Blood. PlosOne. 2011;6:e27539. https://doi.org/10.1371/journal.pone.0027539.

20. Kumar NP, Sridhar R, Banurekha W, Nair D, Jawahar MS, Nutman TB, Babu S. Expansion of Pathogen-Specific Mono- and Multifunctional Th1 and Th17 Cells in Multi-Focal Tuberculous Lymphadenitis. PlosOne. 2013;8(2):e57123.

21. Marín ND, Paris SC, Rojas M, Garcia LF. Functional profile of CD4+ and CD8+ T cells in latently infected individuals and patients with active TB. Tuberculosis. 2013:93:155-66.

22. Sutherland JS, Adetifa IM, Hill PC, Adegbola RA, Ota MO. Pattern and diversity of cytokine production differentiates between Mycobacterium tuberculosis infection and disease. Eur J Immunol. 2009;39:723-9.

23. Caccamo N, Guggino G, Joosten SA, Gelsomino G, Di Carlo P, Titone L, Galati D, Bocchino M, Matarese A, Salerno A, Sanduzzi A, Franken WP, Ottenhoff TH, Dieli F. Multifunctional CD4(+) T cells correlate with active Mycobacterium tuberculosis infection. Eur J Immunol. 2010;40:2211-20.

24. Adekambi T, Ibegbu CC, Cagle S, Kalokhe AS, Wang YF, Hu Y, Day CL, Ray SM, Rengarajan J. Biomarkers on patient T cells diagnose active tuberculosis and monitor treatment response. J Clin Invest. 2015;125:1827-38.

25. Wilkinson KA, Wilkinson RJ, Pathan A, Ewer K, Prakash M, Klenerman P, Maskell N, Davies R, Pasvol G, Lalvani A. Ex vivo characterization of early secretory antigenic target 6-specific T cells at sites of active disease in pleural tuberculosis. Clin Infect Dis. 2005;40:184-7.

26. Nemeth J, Winkler HM, Zwick RH, Rumetshofer R, Schenk P, Burghuber OC, Graninger W, Ramharter M, Winkler S. Recruitment of Mycobacterium tuberculosis specific CD41 T cells to the site of infection for diagnosis of active tuberculosis. J Intern Med. 2009;265:163-8.

27. Ribeiro-Rodrigues R, Resende Co T, Rojas R, Toossi Z, Dietze R, Boom WH, Maciel E, Hirsch CS. A role for CD4+CD25+ T cells in regulation of the immune response during human tuberculosis. Clin Exp Immunol. 2006;144:25-34.

28. Baecher-Allan C, Wolf E, Hafler DA. MHC Class II Expression Identifies Functionally Distinct Human Regulatory T Cells. I Immunol. 2006;176:4622-463.

29. Hall BM, Tran GT, Verma ND, Plain KM, Robinson CM, Nomura M, Hodgkinson SJ, Do Natural T. Regulatory Cells become Activated to Antigen Specific T Regulatory Cells in Transplantation and in Autoimmunity? Front Immunol. 2013;2:4-208. https://doi.org/10.3389/fimmu.2013.00208.

30. Hall AO, Beiting DP, Tato C, John B, Oldenhove G, Lombana CG, Pritchard GH, Silver JS, Bouladoux N, Stumhofer JS, Harris TH, Grainger J, Wojno ED, Wagage S, Roos DS, Scott P, Turka LA, Cherry S, Reiner SL, Cua D, Belkaid Y, Elloso MM, Hunter CA. The cytokines interleukin 27 and interferon- $\gamma$ promote distinct Treg cell populations required to limit infection-induced pathology. Immunity. 2012 37(3):511-23. https:/doi.org/10.1016/j.immuni.2012.06. 014.

\section{Ready to submit your research? Choose BMC and benefit from:}

- fast, convenient online submission

- thorough peer review by experienced researchers in your field

- rapid publication on acceptance

- support for research data, including large and complex data types

- gold Open Access which fosters wider collaboration and increased citations

- maximum visibility for your research: over $100 \mathrm{M}$ website views per year

At $\mathrm{BMC}$, research is always in progress.

Learn more biomedcentral.com/submission 